AIAA-2002-2178

\title{
LASER PHOTON FORCE MEASUREMENTS USING A CW LASER
}

\author{
P.A. Gray \\ ICRC \\ Huntsville, AL 35816 \\ D.L. Edwards* \\ M.R. Carruth, Jr." \\ ED31 Environmental Effects Group \\ Marshall Space Flight Center, AL 35812
}

\begin{abstract}
The photon force resulting from the non-damaging impact of laser derived photons on a metallic target was measured using a vacuum compatible microbalance. This experiment quantitatively verified that the force resulting from laser photons impacting a reflective surface is measurable and predictable. The photon wavelength is $1064 \mathrm{~nm}$ and the laser is a multi-mode $300 \mathrm{~W}$ Nd YAG continuous wave (CW) laser.
\end{abstract}

\section{INTRODUCTION}

There are two main sources of photons for use in photonic propulsion schemes, the first of which is sunlight. The sun is considered to be an unlimited power source, but photon power densities are low requiring large sail areas to capture enough photons to provide usable thrusts. The second source of photons would be man made and most likely in the form of a laser. Unlike the sun, a laser is not an unlimited power source. There are benefits to both sources of photons but for the purpose of this paper a laser is considered as the source of photons. As previously reported, a vacuum compatible micro-balance was used to measure photon force derived from an X25 solar simulator. Spectrum '. In this paper, the same technique was used to measure the photon force resulting from a $\mathrm{CW}$ laser. Figure 1 illustrates the experimental setup.

* Member, AIAA

Copyright (C) 2001 by the American Institute of Aeronautics and Astronautics, Inc. No copyright is asserted in the United States under Title 17, U. S. Code. The U.S. Government has a royalty-free license to exercise all rights under the copyright claimed herein for governmental purposes. All other rights are reserved by the copyright owner.

\section{APPARATUS}

The test chamber for this experiment consists of a 6 way vacuum cross with 10 inch Conflat ${ }^{\circledR}$ flanges. The test chamber is mounted on a $600 \mathrm{l} / \mathrm{s}$ ion pump. A picture of this vacuum system is shown in Figure 2. The laser beam passes through a $-250 \mathrm{~mm}$ focal length expanding lens then through a standard glass view port. After it passes through the view port, a $45^{\circ}$ turning mirror directs the expanded laser beam to the target.

The laser being used for this experiment is a Quantronix Model 118, 300W peak output Nd YAG $\mathrm{CW}$ laser. The $19 \mathrm{~mm}$ diameter YAG laser beam is expanded using a $-250 \mathrm{~mm}$ lens. The laser and lens system is shown in Figure 3.

The force measuring device is a CAHN model D101 vacuum compatible microbalance. The sample is suspended from the balance with a long Nichrome wire. As seen in Figure 1, gravity is acting on the target. It is being held by the microbalance, which precisely measures its weight. When the laser is directed onto the target and the photons impinge on it, they provide an upward force. This is measured by the microbalance as a decrease in target weight. The sample consists of a thin stainless steel plate, shown in Figure 4. The thin plate was chosen because it is lightweight and has a high damage threshold.

Laser power measurements were obtained, using a Molectron Model PM300F-50. The power meter was located after the expanding lens and before the chamber window. This power meter is fan cooled and has a 2 inch diameter detector surface. The detector surface is almost spectrally flat. The power meter has an overall accuracy of $3 \%$. 


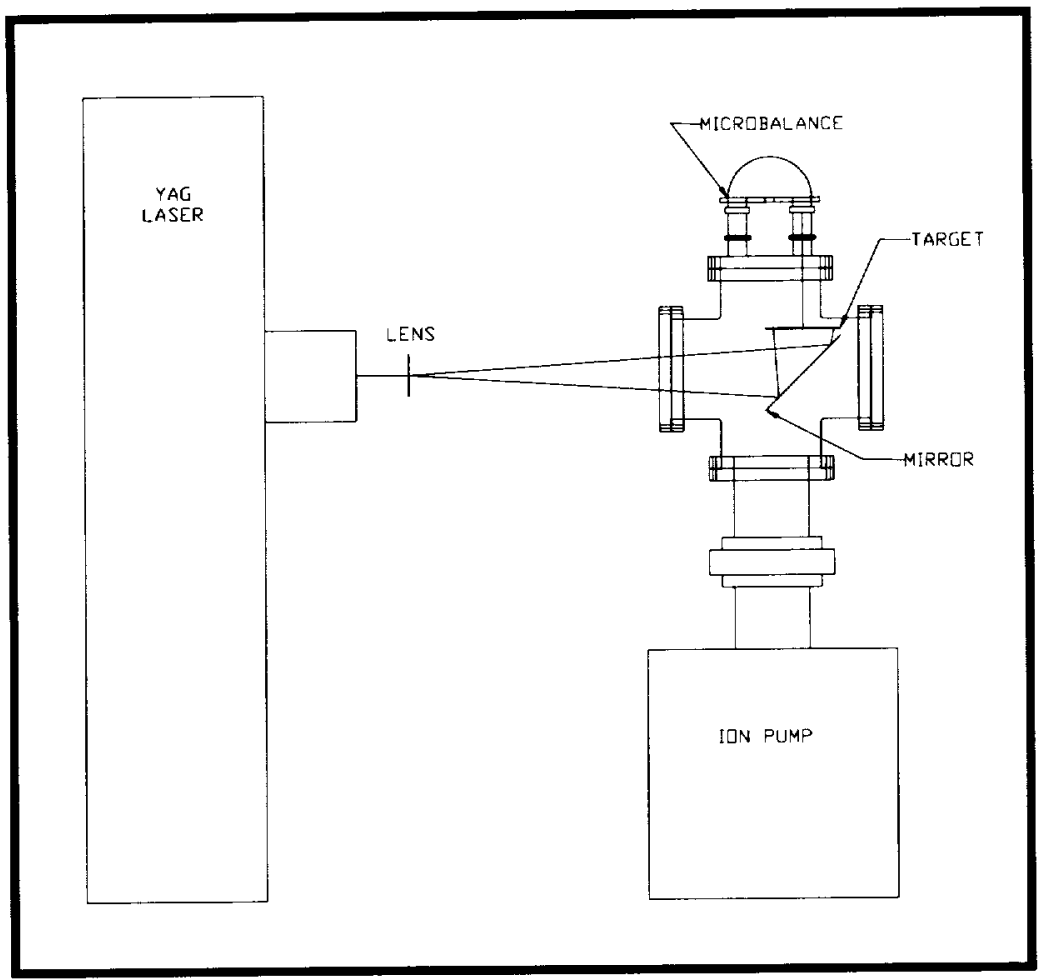

Figure 1 Schematic of experimental setup

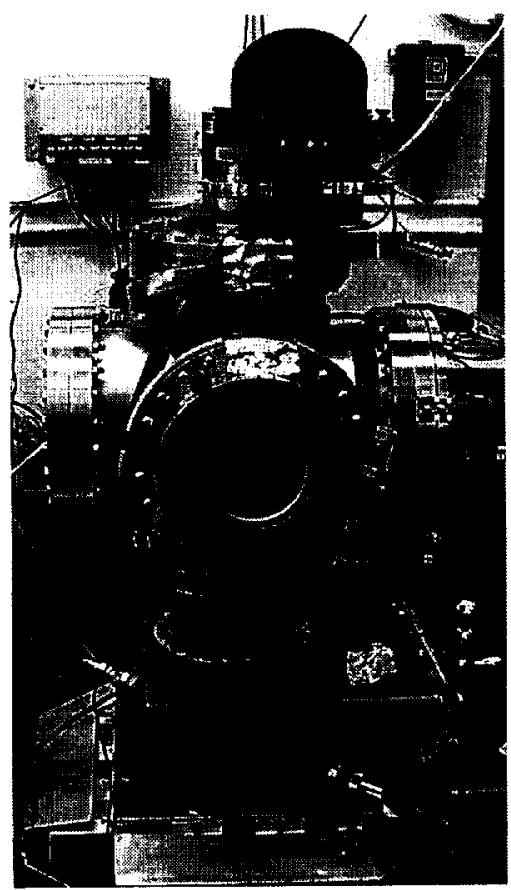

Figure 2 Vacuum Chamber 


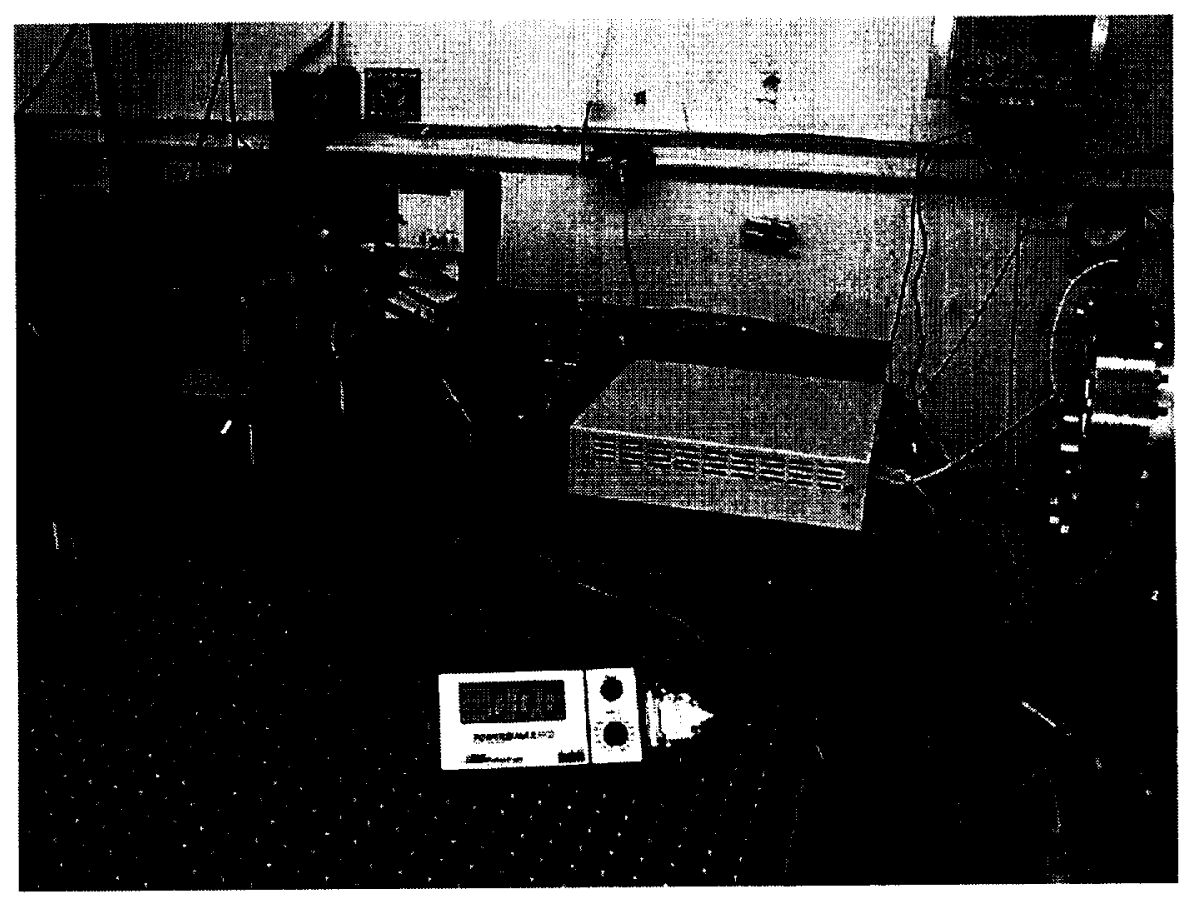

Figure 3 Photo of optical setup

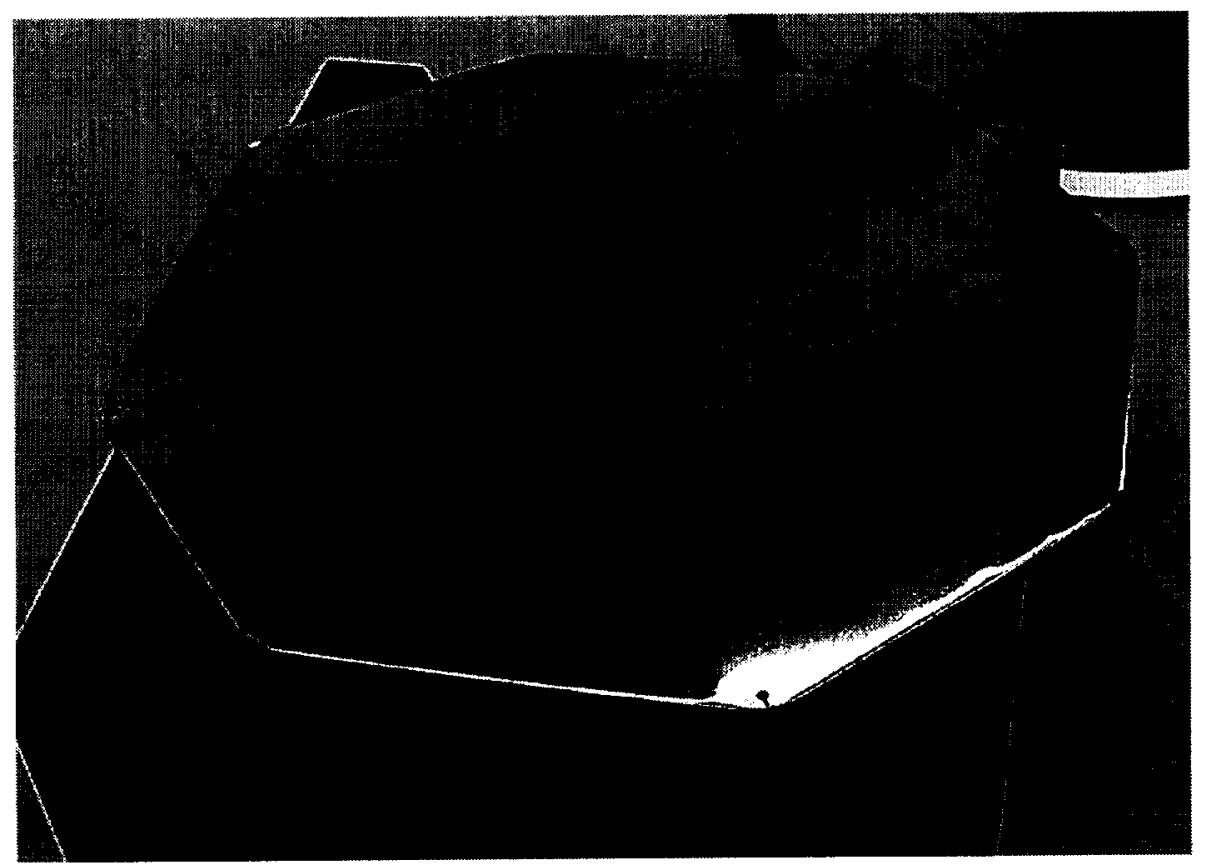

Figure 4 Stainless steel target

3

American Institute of Aeronautics and Astronautics 
The accuracy for a ratio of two measurements in the same sensitivity range at the same wavelength is $1 \%$.

\section{THEORY}

The concept of photon pressure is based on photons having momentum that can be transferred to an object. From Planck's law the energy, E, of a photon is:

$$
\mathrm{E}=\mathrm{hv} \text {, }
$$

where $h$ is Planck's constant and $v$ is the frequency of the photon. In order to make use of this equation we must relate the energy to the momentum. This can be done using equation (2) from special relativity theory:

$$
E^{2}=m_{0}^{2} c^{4}+p^{2} c^{2}
$$

where $\mathrm{p}$ is the momentum of the particle, $\mathrm{m}_{0}$ is the rest mass of the particle, and $c$ is the speed of light in vacuum. Since a photon has zero rest mass, equation (2) reduces to equation (3):

$$
\mathrm{E}=\mathrm{pc} \text { or } \mathrm{p}=\mathrm{E} / \mathrm{c} \text {. }
$$

Therefore, photons of higher frequency will have higher momentum than photons of lower frequency. For propulsive purposes, the total sum of the energies from all photons of all energies $\left(E_{T}\right)$ is the important quantity for determining the total momentum for all photons hitting a reflective surface.

Momentum for a moving object is also defined as:

$$
\mathrm{p}=\mathrm{Ft}
$$

Where $\mathrm{F}$ is the force applied over time, $\mathrm{t}$.

Substituting equation ( 3 ) in equation (4) gives:

$$
\mathrm{F}=\mathrm{E}_{\mathrm{T}} / \mathrm{ct}
$$

The total power of the photons (I) will be defined as:

$$
\mathrm{I}=\mathrm{E}_{\mathrm{T}} / \mathrm{t} \text {. }
$$

Since the force can be related to the energy, the momentum variation due to photons of different frequencies doesn't have to be considered. All that is required is that the total photon energy at the surface be known. Therefore, the photon force, $F$ in Newtons is given by:

$$
\mathrm{F}=\mathrm{V} / \mathrm{c} \text {, }
$$

where $I$ is the total power from the laser in Watts.

For a reflective surface, there is also a momentum contribution due to the reflected photons. A general equation for the photon force on a reflective surface is giving by:

$$
F_{\text {total }}=(I / c)(1+R)
$$

where $\mathbf{R}$ is the reflectance of the target material at laser wavelength of $1064 \mathrm{~nm}$. For the stainless steel plate $R=$ 0.79 .

A general equation that includes optical component losses is given by:

$$
F_{\text {calc }}=(I / c)(1+R)(\eta)
$$

where $\eta$ is the term that takes into account losses through optical components. For this paper $\eta=0.868$.

\section{EXPERIMENTAL RESULTS}

The laser was passed through an expansion lens to reduce the energy density. The lens focal length was $250 \mathrm{~mm}$ to make the divergence angle as small as possible to reduce off axis losses. The divergence angle was less than $3^{\circ}$. Since the cosine of this angle is approximately one, the effect of angle was neglected. The laser power was measured after the diverging lens and before the vacuum chamber window. Figure 5 shows the optical components and the location of the power meter during measurements.

To measure the optical losses through the vacuum chamber window and off the $45^{\circ}$ turning mirror, the window and mirror were removed from the vacuum chamber. The throughput of the window-mirror combination was measured by placing the laser power meter in front of the two elements and then behind them. The ratio of the measurements gave the throughput of the two elements. The positions of the power meter to obtain this ratio are shown in Figure 6 . The accuracy of this ratio is better than the power meter specification of $3 \%$. Systematic errors are ratioed out and the measurements were made at almost the same magnitude so linearity is not a large source of error. The combined error of this measurement is $1 \%$ as stated by the factory. 


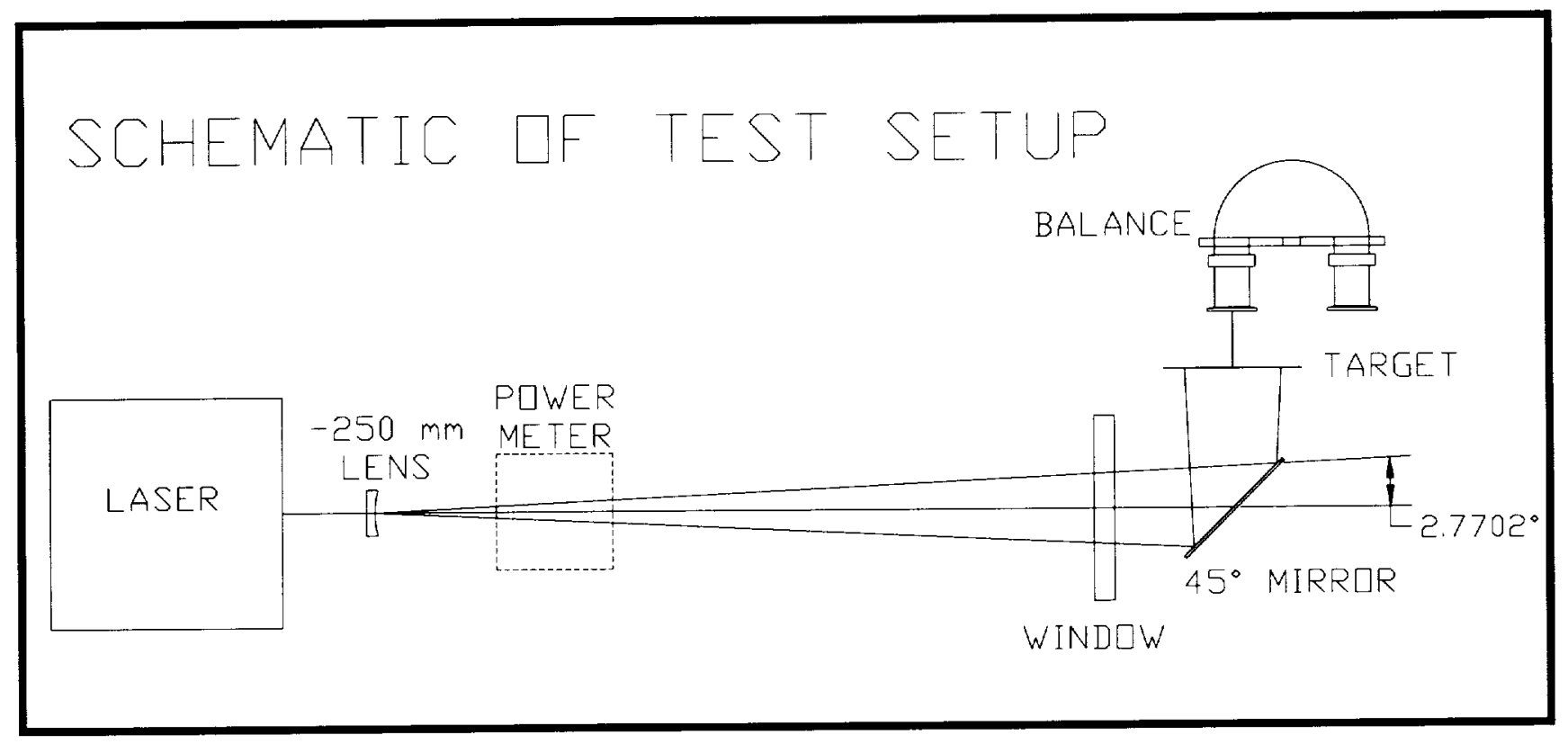

Figure 5 Optical component schematic

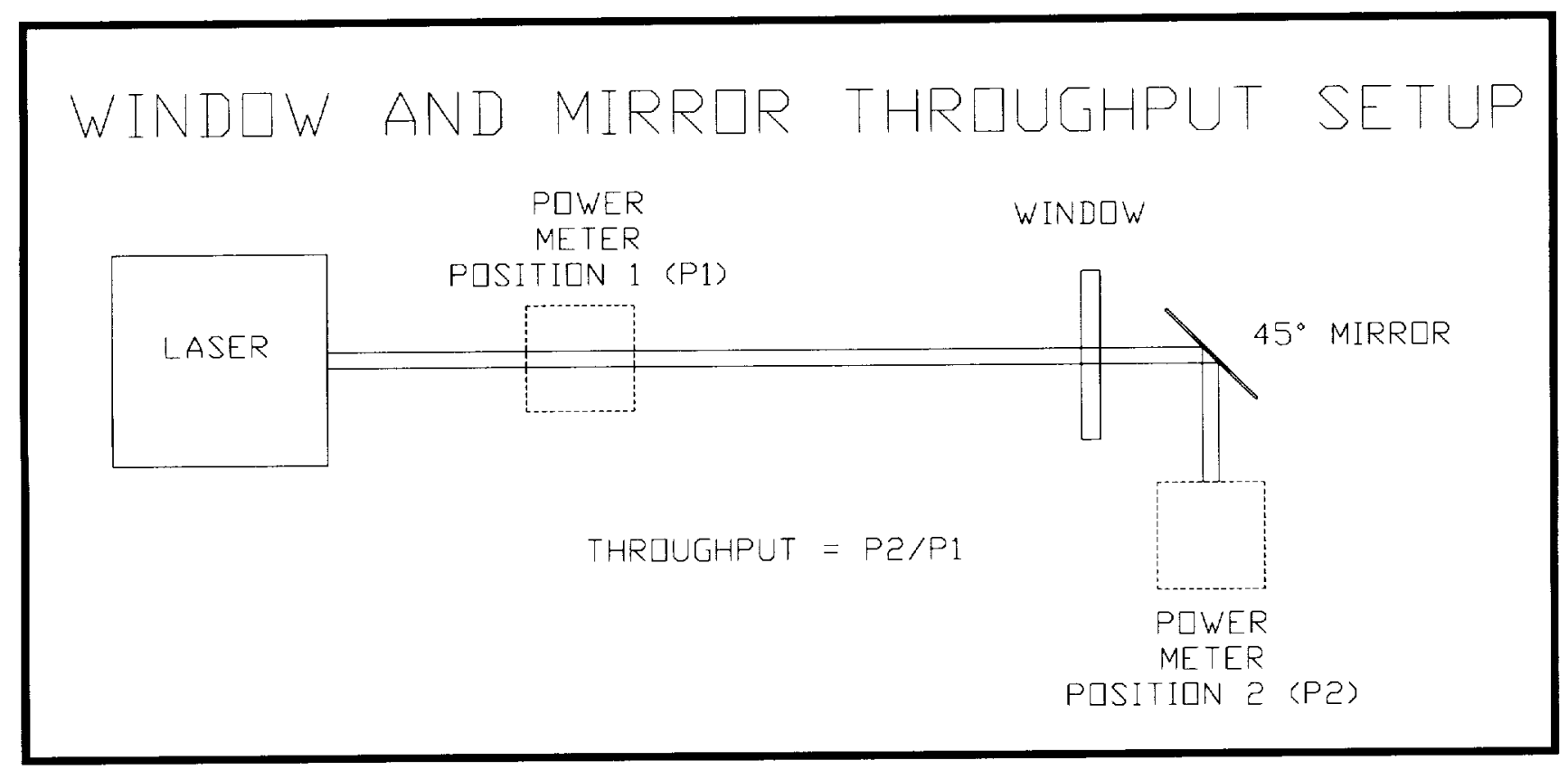

Figure 6 Optical layout for throughput measurements 
The error in the calculated force $\left(\mathrm{F}_{\text {calc }}\right)$ was determined to be $3.56 \%$ using propagation of error techniques ${ }^{2}$. The error in $\mathrm{F}_{\text {calc }}$ is the combination of the absolute accuracy of the power meter of $3 \%$ and the relative $1 \%$ accuracy for the optical component throughput ratio. The measured force $\left(F_{m}\right)$ error was estimated to be $2.66 \%$ based on the standard deviation of 19 measurements. Actually the $F_{m}$ standard deviation number is the standard deviation of the $\mathrm{F}_{\mathrm{m}} / \mathrm{F}_{\text {calc }}$ ratio. The chief component of error is the repeatability of the balance since we know the repeatability of the power meter to be less than $1 \%$. It was impossible to calculate a standard deviation on the measured force alone since it must be normalized to the power of the laser at the time the measurement was taken. This ties the repeatability of the $F_{m}$ number to the power meter as well as the balance. At the small force levels, the resolution of the balance is the main source of error. The effect of this resolution limit is realized in the standard deviation number. Table 1 shows the data taken for this experiment.

As a measure of the validity of the photon force measurements, the measured force $\left(F_{m}\right)$ was divided by that predicted from laser power measurements $\left(\mathrm{F}_{\text {calc }}\right)$. $F_{\text {calc }}$ was calculated using the laser power measurements and equation (9). Since both numbers have error associated with them, a combined error for the ratio, of $4.1 \%$, was calculated using the technique of the propagation of errors. The value of the ratio was $\mathrm{F}_{\mathrm{m}} / \mathrm{F}_{\text {calc }}=0.97$ or $97 \%$.

Since most $\mathrm{F}_{\mathrm{m}} / \mathrm{F}_{\text {calc }}$ ratios points were less than $100 \%$ there must be some systematic error, i.e. an unidentified loss mechanism. This could be attributed to scattering of reflected light off the sample in a direction not normal to the surface. Any scattered non-normal ray leaving the target surface will have a vector component that can be resolved into components that are normal and parallel to the target surface. The component that is parallel to the target surface will not produce an upward force on the target. The surface was not perfectly specular so this could be a source of error. In addition, the power detector for the laser was calibrated, by the factory, at $512 \mathrm{~nm}$ and the laser wavelength is $1064 \mathrm{~nm}$. The ratio between the detector reflectance at $512 \mathrm{~nm}$ divided by the reflectance at $1064 \mathrm{~nm}$ is 0.983 . These reflectance numbers were obtained on a portable spectro-reflectometer. This changes the $\mathrm{F}_{\mathrm{m}} / \mathrm{F}_{\text {calc }}$ ratio from 0.97 to 0.986 or $98.6 \%$.

An example of force data measured on the stainless steel target is shown in Figure 7. Power measurements were taken periodically to compensate for power drift in the laser intensity.

\section{SUMMARY}

The measurements indicate that the force from laser photons can be accurately measured with a vacuum compatible microbalance. This technique provided repeatable and reliable laser photon force data. Future work will involve the use of actual sail materials. With the current setup the laser energy density is too intense for use on thin polymeric materials. Two factors that will improve this problem are increasing the beam diameter by the use of a larger vacuum chamber and sample, and changing the distribution of energy in the beam from a cone shape to a top-hat shape. Both of these techniques will reduce target hotspots.

The results of this experiment prove that lasers can be a source of photonic propulsion assuming the problems of transmission over long distances can be solved. Lasers can be used as the sole source of propulsion or they can be used in conjunction with sunlight to augment conventional solar sails. Lasers may also be used when a spacecraft is too far away from the sun for sunlight to be a viable source of photons.

\section{REFERENCES}

1. P. A. Gray, D.L. Edwards, M. R. Carruth, Jr., Preliminary Photon Pressure Measurements Using a Solar Simulator, AIAA Conference Reno Nevada, January 8-11, 2001, \#2001-1136.

2. P. R. Bevington, Data Reduction and Error Analysis for the Physical Sciences, McGraw-Hill, 1969.

\section{ACKNOWLEDGMENTS}

The authors gratefully acknowledge the support of John Cole in the Advanced Space Transportation Program (ASTP) office. 
Table 1 of Test Data

\begin{tabular}{|l|r|c|c|c|}
\hline Run\# & $\begin{array}{l}\text { Power } \\
(\text { Watts })\end{array}$ & $\begin{array}{l}\text { Fcalc) Calculated Force }(\mu N) \\
\text { Based on Laser Power }\end{array}$ & Measured Force $(\mu N)$ & Fm/Fcalc \\
\hline run1 & 90.0 & 0.458 & 0.451 & 0.985 \\
\hline run1 & 92.4 & 0.470 & 0.461 & 0.981 \\
\hline run1 & 93.1 & 0.474 & 0.468 & 0.987 \\
\hline run1 & 147.0 & 0.748 & 0.736 & 0.983 \\
\hline run2 & 93.3 & 0.475 & 0.481 & 1.011 \\
\hline run2 & 94.5 & 0.481 & 0.491 & 1.019 \\
\hline run2 & 95.4 & 0.486 & 0.500 & 1.029 \\
\hline run3 & 197.0 & 1.003 & 0.998 & 0.995 \\
\hline run3 & 197.5 & 1.006 & 0.984 & 0.978 \\
\hline run3 & 198.0 & 1.008 & 1.037 & 1.029 \\
\hline run4 & 186.5 & 0.949 & 0.928 & 0.978 \\
\hline run4 & 187.5 & 0.955 & 0.957 & 1.002 \\
\hline run4 & 188.5 & 0.960 & 0.973 & 1.014 \\
\hline run5 & 122.0 & 0.621 & 0.602 & 0.969 \\
\hline run5 & 124.0 & 0.631 & 0.591 & 0.936 \\
\hline run5 & 125.0 & 0.636 & 0.604 & 0.948 \\
\hline run6 & 231.5 & 1.178 & 1.128 & 0.957 \\
\hline run6 & 231.5 & 1.178 & 1.150 & 0.976 \\
\hline run6 & 231.5 & 1.178 & 1.134 & 0.962 \\
\hline & & & Average & 0.986 \\
\cline { 2 - 5 } & & & Standard Dev & 0.026 \\
\cline { 2 - 5 } & & $\%$ Standard Dev. & 2.662 \\
\hline
\end{tabular}




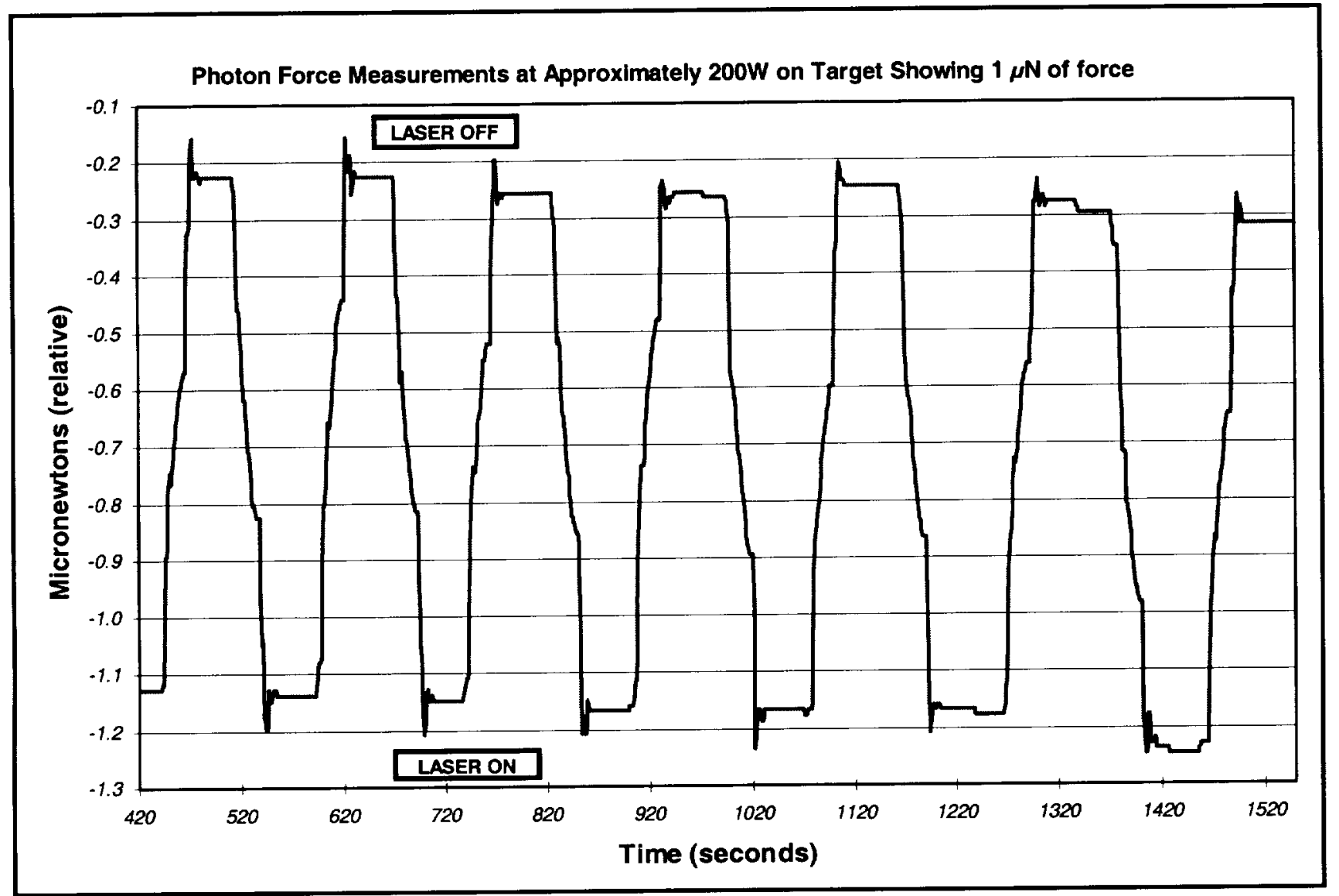

Figure 7 Laser force data. 